\title{
Services for the Elderly in Israel: Privatization or Nationalization-An Unending Dilemma-A Reflection
}

\author{
Avi Bitzur ${ }^{1}$, Mali Shaked ${ }^{2}$ \\ ${ }^{1}$ Ph.D., Head of the Department of Gerontology, Faculty of Education, Beit Berl Academic College, Former Director of \\ the Ministry of Senior Services, Government of the State of Israel, Israel \\ ${ }^{2}$ Chief of Staff of the Friends of Meir Medical Center Foundation, Kfar Sava, holds a Bachelor's degree in Health Systems \\ Management with a major in Applied Gerontology and currently completing a Masters degree in Business Administration \\ specializing in Human Resources, Israel \\ Correspondence: Avi Bitzur, Ph.D. Head of the Department of Gerontology, Faculty of Education, Beit Berl Academic \\ College, Israel.
}

Received: March 12, 2019

Accepted: March 25, 2019

Available online: April 1, 2019

doi:10.11114/ijsss.v7i3.4189

URL: https://doi.org/10.11114/ijsss.v7i3.4189

\begin{abstract}
The world in which we live is aging at a dizzying pace and expressions like "70 is the new 50" or the creation of concepts such as the "Silver Tsunami", a nickname for the aging baby-boomer generation, have become an inseparable part of the reality in our society.

On the one hand, the spread of aging is a welcome phenomenon - a sort of solution to the great human effort to reach immortality. On the other hand, however, old age can be perceived as a period burdened by economic, social and health-related challenges and it is becoming more and more clear that throughout the world, and in Israel in particular the focus of this article - we must begin to prepare systems and services for the provision of rapid and comprehensive solutions for the tsunami of aging that befalls us. This stems from an understanding that the services we have in place today are not sufficiently prepared to handle the range of challenges and issues that will arise as a side effect of this phenomenon.

The dilemmas that come hand in hand with the aging of our population are innumerable, however five particular issues stand out: the first is who should be responsible for the elderly and their care - the government or the person's family? The second: Should all of the elderly receive the same care or should the treatment assistance vary differentially - meaning each elderly person should receive care according to his or her economic, social and health status and receive only according to their needs? The third is, should we provide assistance to the elderly directly (e.g. specific medications) or should the elderly receive financial assistance equivalent to the value of their needs and should we hope that they purchase the relevant medications, for example, and not something else instead? The fourth dilemma is: should we provide assistance for specific projects or should we work on long-term solutions through legislation to provide care and assistance to the elderly? Fifth, which is also the main questions, is should the services provided be privatized or should the treatment be the responsibility of the state and its institutions?

The question of privatization or nationalization is the main focus of this article, and while we do not pretend to offer a firm stance on the issue, the authors offer to shed some light on the basic concepts associated with our aging population and how we as a society might handle these issues from the perspective of comparison between privatization versus nationalization of services rendered. The main focus of this article will be around the issue of the residential arrangements for the elderly: Mainly - should the elderly move into what are typically called "old age homes" or should we allow for "Aging in Place" - an approach that favors allowing the elderly to remain in their own homes for the remainder of their lives. Which is the most favorable solution? This issue also falls under the dilemma of whether or not homes for the aging as one possible solution should be a state-provided service or if "aging in place" will result in the privatization of the services granted to the elderly.
\end{abstract}

The focus of this article is the situation in Israel, a country in which a significant portion of the population is elderly and where, by $2035,15 \%$ of the population will be considered senior citizens. We will present the dilemma through the lens of the situation in Israel. The article shall begin with an introduction offering an in-depth examination of the dilemma 
presented. We will continue by presenting basic concepts from the general literature in the field of gerontology available today. We will then examine the situation in Israel between the years 2017-2019 and conclude by examining the concepts of privatization and nationalization in regards to services for the elderly, while once again emphasizing that comprehensive solutions to these dilemmas are unlikely to be reached in the near future.

Keywords: old age, privatization, nationalization, housing for the elderly, aging in place, elderly care facilities

\section{Introduction}

"Violence, humiliation, cursing and threats - a Haifa nursing home employee could not remain silent any longer after witnessing the behavior of his colleagues and documenting it with a hidden camera," (Mizrahi, 2017).

A few months ago, a case was reported in Haifa of elderly people being abused in a scene that looked like a horror movie. The elderly residents were being hit with pillows, their hair was pulled and a diaper was thrown at an elderly man's face. To the authors' regret, these are not isolated incidents but rather part of a growing phenomenon. Essentially, the cases that have been revealed to date are only the tip of the iceberg. Among the more alarming figures is that more than 22 thousand people are currently being cared for in homes for the aging around Israel. Most of these homes are private facilities, and the question remains - does this incident indicate the need for management of services for the aging on a national scale or should these facilities remain in private hands? Are basic needs such as food and drink, assistance with bathing, dressing, and medical care being provided as needed? The authors ask a number of questions, such as: Do our elders, the founders of our nation, feel safe within the walls of these institutions? Does the problem stem from a lack of oversight by the country? Are these incidents limited to private institutions? The population of the elderly in the world is growing, and furthermore, the elderly population itself is getting older. In the past, it was acceptable to refer to those 65 years and older as senior citizens. Today, we must take into consideration the subcategories that exist within the population of senior citizens as within the population of senior citizens there are gaps of 30 years and people at different ends of this spectrum have wildly different needs (Brodetzky, 2003 pp. 289-313). In Israel in 2017, the elderly made up 11\% of the general population, numbering 930 thousand people. In 2020, the rate of elderly in the general population will be $14 \%$, which is more than one million elderly individuals in the population. The statistics are similar around the world and the problems, dilemmas and challenges that arise from these figures are numerous. There is no doubt that the world in general and Israel in particular must prepare for the tsunami of aging that is heading towards us.

The processes of aging and the epidemiology of old age point to an increased vulnerability during this stage of life with an increased rate of illness and disability accompanied by a combination financial, social and health-related difficulties (Bitzur, 2017).

The burden of caring for the elderly often falls to their families. The families face the dilemma of whether to allow their elderly relatives to "age in place" or whether to transfer them to a long-term care facility (old age home), in its various forms. Some family members are unable to take part in the responsibilities, leaving the elderly abandoned both by their families and by the government, which had left some of the responsibility for their care in the hands of the families. The lack of government involvement in the care for the elderly is significant in light of the continuing rise in life expectancy. The trend in the aging within Israeli society is similar to that of other developed countries in terms of its general trend towards a decrease in fertility and an increase in life expectancy. The demographic transitions and aging of the population has implications for all age groups. On the one hand, as mentioned previously, aging is considered to be a great achievement of mankind in terms of our ability to prolong life, however it also poses new challenges.

There is no doubt that the topic of aging is a challenging one and includes an entire range of issues associated by various changes such as: changes in living arrangements (in some cases a transition from "aging in place" to a long-term care facility that might be assisted living, general nursing homes, integrated nursing homes for the those requiring part time or full time nursing care), and changes in economic and social status. The perception of the aging experience by the elderly persons themselves is influenced by their level of education, economic status, gender, cultural background, where they live, residential arrangement - aging in place versus in a facility. If the person does live in a facility then is it best for them to be in an old age home owned and supervised by the state (i.e. nationalization of care) or would it be better to choose a different type of ownership for these facilities such as ownership by private entities that operate on a for-profit basis? Is it proper to allow for one of the most delicate and complex areas of welfare to be managed by private individuals or not? Experience shows that within just a few short years, there has been an alarming increase in the crowdedness of long-term care facilities, despite a reduction in the number of positions for employees at these facilities and little oversight by the government. While a reduction in workforce at these facilities might reduce costs, those in charge have forgotten that the welfare of the elderly people in their care must be the guiding principle in the operation of the facilities, and that the neglect, poor conditions and even violence are ostensibly part of the grim and terrifying results of privatization.

Upon examination of the literature on the subject, a number of questions arose for the authors regarding the elderly and aging in general. For example, what is right for the elderly in terms of residential arrangements? What is their status in 
society? How can we eradicate the violence and disparagement on the part of society towards its elderly? How can we fulfill the needs of tomorrow? Where is the best place for the elderly members of our population to live? Should they live in long-term care facilities or in their own homes? For the purposes of this article, we will focus on the dilemma of choosing between privatization and nationalization of care for the elderly members of our population with a full understanding that the large range of challenges is even greater than what we present here. We will attempt to focus on one of the main issues - residential facilities - while focusing on the question of whether to privatize or nationalize the nursing homes as one of the examples of the possible types of residential arrangements for the elderly.

\section{The Elderly, Old Age and Aging - Basic Concepts}

In this section we will focus on the three central concepts facing the dilemma of privatized or nationalized care for the elderly. These basic concepts will serve as the basis for the understanding of aging, however they are only a small sample of the range of definitions of and approaches to the subject of aging.

a. Elderly According to Jewish tradition, the elderly are characterized by wisdom, leadership, and intelligence that has been collected over many years. In Ancient Rome as well, aging was considered to be associated with wisdom, and is never associated with the negative connotations such as weakness, inefficiency, functional impairment or any of the other stereotypes associated with aging in our society today. In the $20^{\text {th }}$ and $21^{\text {st }}$ centuries, the attitude towards aging changed. Today, wisdom is associated with youth, innovation and technology. Technology prevents the elderly from sharing advice and offering guidance and the status of elderly in our society has become associated with weakness, leaving us with an older generation often perceived of as weak and unproductive. A person, who one moment before their $67^{\text {th }}$ birthday was thought of as healthy and active crosses a line on their $67^{\text {th }}$ birthday, inhabiting a status of being old and unproductive. This ageist approach, a cross-cultural, global phenomenon is seen to different degrees. On an interpersonal level, there is some aversion to contact or conversation with the elderly. In addition, they are often the objects of jokes or stereotypes, and on an institutional level where the most prominent issue is the resistance to hiring older people. Ageism has extensive implications, among them self-perception - the way in which an old person perceives of him or herself - since we tend to reflect what others think of us, their self-perceived value can be quite low. The perception of the old person's status changes from one culture to another and the more modern a society, the weaker the status of the elderly in contrast to many undeveloped societies.

b. Old Age - From the Jewish perspective, for example, old age is associated with wisdom and its various associated qualities (Kurtz, 2003, pp. 5-7). According to the same source, old age is the age range that delineates the last stage of the average person's life cycle, a stage that comes after middle age. Elsewhere, old age is defined as a state that characterizes the population that has reached longevity and continues in the aging process. Old age is related to a reduction in a person's functional reserves, a reduction in his or her physical and cognitive capabilities as seen in daily activity and a decrease in the ability of the body to resist various environmental stresses, resulting in an increase in morbidity (Brenner, 2001, pp. 5-12).

An additional definition offers old age as a process significant for its accumulation of harmful and irreparable changes within cells and tissues that, over time, increase the risk of disease and/or death.

According to the World Health Organization (WHO), ${ }^{3}$ in the developed world, chronological time fulfills the most important criterion when defining old age. The age of 60 or 65 is roughly the age of retirement in developed countries and serves as the start of old age. (In Israel, old age is considered to begin at age 67 for men and 62 for women). Many people continue to be active and involved in all areas of society as well as the economy as consumers of culture and even in politics well past this age and it can therefore be difficult to rely on chronological age as the variable that defines the elderly.

In Western society, subcategories are used to define old age according to chronicity: "young-old" is used to define ages 65-74, "middle-old" is used for those age 75-84 years and "old-old", or "oldest-old" to define those over the age of 84 years.

All of these definitions of old age rely on a perception that examines the care for the elderly as a reflection of the dilemma on which we intend to focus, privatization versus nationalization, where a prominent issue that arises is whether to see old age as a burden or as an asset to society as the foundation for the provision of necessary care for our elders.

c. The Aging Process - A slow process with a determined end point that involves a reduction in the vitality of an organism and its ability to defend itself against various illnesses that might afflict it and cause its demise (Berman, 1988, pp. 40-56). This process is related to the demographic characteristics of the population of the 
elderly, meaning that the consideration is of an increase in the number of elderly in comparison with the general population (Brodetsky 2003, pp. 289-336).

The phenomenon of aging is a global one, and initial efforts to deal with the matter of aging were already implemented in the early $19^{\text {th }}$ century. Many theories attempted to describe the phenomenon of aging. Hall, for example, connected between the psychological significance and biology, medicine and philosophy and compared aging to a mountain. The ascent to the peak symbolizes the growth and achievement and the descent from the mountain symbolizes the descent into old age. Turner in his model of the curve of reciprocity and maturity described the aging process as a parabola similar to the mountain model. Turner's model described the aging process in three stages where at the peak there is prestige, and the approach to that peak involves a process of learning, creation, social life, while the descent is characterized by a decrease in all of the parameters: a decrease in cognitive abilities, physical abilities, health status and social abilities. The aging revolution is the most important social revolution of our time. Developed countries around the world are progressing rapidly to a state in which the population over the age of 65 will make up one-third of the total population (Machtinger, 2010), a state that stems mostly from reduced reproductive rates that have continued for a number of decades in developed countries and the increase in life expectancy as well as a reduction in mortality, especially among the older age groups. Essentially, the portion of children aged 0-14 in developed countries is falling while the portion of elderly is on the rise, resulting in the inversion in the age pyramid (Bitzur, 2018). This process relates to the demographic change that occurred in countries around the world and caused the aging of the population according to which, for example, by the year 2025, Japan will be the oldest country in the world, population-wise. Israel is a relatively young country in comparison with other developed nations - the portion of elderly in Sweden is twice that of Israel and Israel will therefore be engulfed in the problem of an aging population a few decades later than other developed nations and the aging process is somewhat different than it is in other developed countries (Brodetzky, 2003 p. 158). Changes in reproductive rates and mortality rates fail to explain the aging process in Israel and in addition to these factors; the element of immigration from foreign countries contributes significantly to the number of elderly. The demographic transition and an aging population have far-reaching impact on every age group within society, as well as on the economy and on society's various institutions. While aging is considered to be a great achievement for humankind, it forces society to face new challenges as well. For example, in one of his articles, Yakobovitch states (Inbar, 2014) that the aging process will continue to expand and even grow significantly and the demographic, social, economic, and political implications will affect not only the elderly but also society as a whole and the economy in Israel, and that we must prepare ahead of time and provide a master plan for handling the situation. On a global level, the United Nations (UN) established a plan of action in 2003 regarding everything related to formulation of international standards in social policy for the elderly. It should be noted that Israel is a member in this plan (The Madrid International Plan of Action on Aging). The plan deals with the range of issues including quality of life, safety, healthcare, economy, employment, housing whether aging in place or in a nursing home - and the socio-economic status of the elderly population in the world. The objective of this plan is the development of policy as necessary to ensure that the elderly have a supportive, enabling and safe environment. If this is so, should these parameters be handled by the private market or by the government itself? In order to examine this we will present the case of Israel in the next chapter.

\subsection{Aging in Israel - Data, Types of Facilities and Dilemmas}

In order to examine the dilemma of privatization versus nationalization of services for the elderly in Israel in 2019 , it is worthwhile to begin with a number of parameters regarding Israeli society with regard to the country's older population. From there we will continue with a description of the care facilities that currently exist in Israel and the various types of residential facilities currently available. Throughout our discussion, we will examine the management with presentation of the dilemmas related to aging in Israel.

\subsection{Demographic Characteristics (Zaira, 2017)}

The number of senior citizens - There are roughly 948,000 people above the age of 65 who make up $11.4 \%$ of the general population. Estimates are that by the year 2035 is that there will be 1,750,000 people comprising 14\% of the general population and in 2065 more than 3 million elderly people in Israel. Average life expectancy for women is 84 and for men is 80.7. Sex: Women make up most of the population age 65 and over, measuring $56 \%$ of the elderly. Geographic distribution: The vast majority of senior citizens live in urban areas, and one third of them live in just three cities: Tel Aviv, Jerusalem and Haifa. Entitlement to long-term care benefits: 169,891 senior citizens in Israel over the age of 65 years, $33 \%$ of them, are entirely dependent on assistance. Hospitalization: $36 \%$ of the general hospitalizations (not including labor/delivery) in 2015 were of individuals age 65 and over and $58 \%$ of them were hospitalized in internal medicine 
departments. Health characteristics: roughly $45 \%$ of individuals age 65 and up consider themselves to be in good or very good health and most of them are men. Employment: the rate of employment among individuals age 65 and up in 2016 was $20.4 \%$, of which $64 \%$ were men who worked full time and were employed by an employer (84\%) as opposed to self-employed. Retirement age in Israel: Women - age 62, men age 67. Poverty: the measure of poverty among the elderly is greater than that of the general population and reached $16.9 \%$ in 2016 . The rate of families of elderly who lived in poverty in 2016 was $20.8 \%$ and women and Arabs were poorer. Loneliness: $36 \%$ felt lonely, and most of those were women. The Senior Citizen Pension - Roughly 880,445 people received a senior pension, and $61 \%$ of them were women. Residential: roughly $96 \%$ of elderly individuals live in their own homes, while the remainder lives in residential facilities. Education: The level of education among the elderly is constantly on the rise, $21 \%$ of them have an academic level of education, and men are more educated than women, however the gap is shrinking. Profile of the elderly in Israel - The population is different than the previous generation of elderly people in Israel, they are more educated, more active, more opinionated, however despite this, society discriminates against them with outright ageism and with the same disregard that they held towards the previous generation of senior citizens. The sense of loneliness among the elderly is overwhelming and this is the result of changes that occurred in Israeli society much like in other societies and is related to a perception of intergenerational commitment. With modernization came changes in the family unit, including changes to the patterns and types of families, resulting in a shift in the intergenerational relationships and eventually a weakening of the intergenerational commitment. In recent decades, the family unit has shifted towards a large number of generations in the family with a reduction in the number of individuals in each generation, with four and even five generations alive at one time (Levenstein, 2003, pp. 623-631). One of the results of this shift is a transition from a way of life in which there is an expanded family structure to one with separate living situations. It is at this point that we focus on the main issue, which is living arrangements for the elderly. The prevailing position in Israel and in the world is to allow the elderly to continue living in their home environments from the perspective that continuity is the best thing for the elderly. It is also worthwhile to mention that the cost of living at home is lower than the cost of moving to a residential facility (Kitchener, Harrington, 2008). Aging in place depends on the family's ability to support their aging family member and whether a person can remain in their own home typically depends on the main caregiver. According to the data, the elderly prefer to live in their own homes as they believe that it will allow them to remain more independent with more control over their lives. Perhaps though, this is the result of publications and stigmas surrounding residential facilities as places with limited funding, a lack of staff, and overworked employees, contributing to the violence towards the elderly residents? Sometimes, however, there is no choice but to transfer a person to a living facility, often due to their health status which requires monitoring and medical care, in combination with the family's inability to provide such care on their own (as the family serves as an informal support network) for the care of the elderly. We believe that the international trend and the new family model will also contribute to the transition towards long-term care in a residential facility due to insufficient caregivers within the family unit. There has been a reduction in the ratio between the number of elderly and the number of informal caregivers, which are first and foremost the children of the elderly (Haviv, 2003 pp. 715-732).

In the following chapters we will examine the existing facilities for the benefit of the elderly, the dilemmas related to this topic - privatization or nationalization - and we will attempt to summarize the gaps between them.

\subsection{Long-Term Care Facilities for the Elderly}

Israel does not currently have a comprehensive social policy in the field of aging long-term care for the elderly (Yakobovitch, 2014 pp. 15-35). There is no single entity responsible for policy development and essentially the status in Israel is that every government ministry establishes its own policy guidelines for its areas of responsibility. An example of this is the split that exists in the care provided at long-term care facilities in which the care is the responsibility of the Ministry of Welfare, which is in charge of placement of the those requiring partial nursing care, while the Ministry of Health is responsible for the placement of patients requiring fulltime care and those with dementia. Each of them has a different set of eligibility rules, separate budgets and separate supervision. There are situations in which the responsibility shifts from one ministry to the other and the people harmed by this are the elderly and their families. It is therefore necessary to establish comprehensive policy plans that might solve the multiplicity of governmental bodies charged with caring for the elderly.

What is long-term care? Long-term care is includes the care and services provided to senior citizens on an ongoing basis in the various facilities that provide residential services to the elderly, from assisted living to nursing homes. The objective of long-term care is to allow elderly individuals with physical disabilities to maintain their health, quality of life, welfare and independence in the best manner possible. The policy in terms of these services is determined for the most part by two governmental offices: the Ministry of Labor and Welfare and the Ministry of Health. This policy is based on a system of ideology, values, and political and economic considerations that make the long-term care facilities into a complex, multidimensional and fragmented system. Due to a reduction in the power of the welfare state to ensure the continued provision of long-term care, there has been an increasing trend in many countries, including in Israel, to return the 
responsibility for long-term care to the families and the community (i.e. the informal support networks for the elderly), which would provide the required treatment. However the trend of aging in the world and the resulting reduction in the availability of caregivers within these informal care networks will eventually result in an increase in the need for institutional facilities. For that reason, the government must be more involved and encourage the development of public alternatives for the treatment of the elderly, specifically the elderly requiring full-time care. While some of this will be solvable by creating solutions in the community setting, it is necessary to increase and diversify the number of spaces at the various facilities.

In Israel there are 304 facilities for long-term care currently under the supervision of the Ministry of Health and 167 facilities currently under the supervision of the Ministry of Welfare, of which 75 are dedicated to the regular elderly population (i.e. those not requiring medical care) and 92 integrated facilities that are designated for those who require some care and those who are relatively independent.

One of the oldest and most important dilemmas regarding aging is who is responsible for the care for and support of the elderly? Are they the sole responsibility of the family (i.e. the informal system), or is the government (a more stable option which is centralized and has more readily available resources) responsible? In general, there are expectations that the country will return the responsibility to the citizens when they necessary. Litwak, in his article (Litwak 1985) claims that there is no such thing as a formal system capable of providing solutions to all of the needs of the elderly without the informal support system, and that the formal and informal systems complement each other. Another approach says that Israel's policy is that the state-provided care for the elderly is intended to complement the care provided by the family. The main question, however is, should care be provided in the community (i.e. "aging in place") or should care be provided in an institutional framework (long-term care)? And if care is provided within an institutional framework, will the current situation allow the elderly to age with dignity and safety? Or should we examine if there is a need for nationalization or privatization? That is what we wish to present in this article.

"Aging in place" is a guiding principle for providing solutions to the various and complex needs of the elderly (Yakobovitz, 2014, pp. 15-35) that can be administered through a network of community services. The prevailing approach in the world and in Israel today is to allow the elderly to "age in place" and remain in their homes.

The policy of "aging in place" is the result of the approach that says that the institutional treatment (which will be described later on) comes at a massive cost to the public and therefore the trend aims to provide care in the community setting - a more economic option intended to reduce escalation in terms of the use of public funds. In recent years there has been a reduction in the state's power to ensure continuation of provision of long-term care and therefore there is an increasing tendency in Israel and around the world to invest in "aging in place" while providing community services, beyond the auxiliary care. We must consider the implementation of legislation that will assist the elderly and protect them and ensure that each and every individual will be familiar with the institutions that provide them with care in order to allow individuals to take advantage of their rights. This requires the establishment of a single system with a single case manager.

The community services that currently exist fall under two main categories:

- Services provided within the elderly person's home that are intended to provide solutions to physical and social needs of the elderly person and complement the care provided by the family. This category includes in-home care, assistance with daily chores, and auxiliary equipment, and these services are provided as part of the Long-Term Care Insurance Law (1998), which reflects the idea that the responsibility for providing care for the elderly lies in the hands of the family and that the government provides adjunct services in addition to what the family provides.

- The second category includes services provided outside of the elderly person's home and this category includes day centers, clubs and recreational facilities, supportive communities/neighborhoods that have housemasters in charge of the elderly individuals residing there.

In fact, $97 \%$ of the elderly people living in Israel are currently "aging in place", as it offers them an opportunity to maintain their patterns of behavior and conduct their lives as a direct continuation of their lives prior to retirement and old age, offering them safety, independence, and a familiar environment. Remaining in their own homes provides them with a sense of safety and they are less prone to being exposed to neglect and violence. They are not interested in moving into long-term care facilities, which they consider to be unworthy. The alternative to "aging in place" is moving into a facility, which is most often selected when elderly individuals do not have an opportunity to "age in place" at which point the option of placement in an institution is considered.

The main reasons for placement in an institution include: 
- Poor health and function - With the increase in age we also see an increase in morbidity among the elderly and significant difficulty in continuing to maintain a household independently.

- Loneliness - The first enemy of aging, and one of the most significant problems that the elderly face is to be alone and not part of a group (Dror 2014, pp. 80-84)

- The decision to place a person in a facility belongs to the elderly person and their family, however the referral for placement can be made by additional entities such as the Ministry of Welfare via a social worker, the Ministry of Health, the local authorities and more. Selection of a facility is typically made based on the elderly person's status, or more accurately based on his or her ability to handle daily tasks. There is a wide range of definitions and the following are a number of central ones:

- Independent Elderly Person - A person who is able to perform activities of daily living (ADL) without assistance. (Ronen, 2018)

- Dependent Elderly Person - A person who, due to his or her reduced capabilities, requires partial assistance in activities of daily living.

- Elderly Person Requiring Full-Time Care - An elderly person who, due to his or her health status or disabilities as a result of chronic illness or chronic problems, requires regular medical monitoring and daily care.

\subsection{Types of Facilities that Currently Exist in Israel}

The increase in age among the elderly is associated with an increase in the rate of elderly people with disabilities who require assistance due to physical, cognitive (i.e. dementia) or combined disabilities. The data indicate that $16.7 \%$ of all elderly people have some disability in terms of their ability to function and this rate continues to rise as the average age of the elderly increases (Yakobovitch, 2014 pp. 15-35). Demographic data regarding the elderly individuals living in facilities shows that among those ages 85 and over, the number of women in facilities is nearly double that of the number of men, there are more Jewish residents than Arab residents and there is a high rate of elderly who are not married. Despite the dominance regarding the type of living arrangements in the community, there is a clear trend towards growth in the rate of elderly with disabilities living in facilities, and in the previous chapter we discussed that this is one of the main reasons that people move into such facilities in the first place. If we compare Israel to other developed nations, the rate of people living in nursing homes is relatively low. In Holland, for example, the rate of elderly living in institutions is double that of Israel (Be'er, 2004).

There are two types of facilities for long-term care: institutional facilities (operated by the state) and community facilities (which are private).

Institutional facilities these facilities are under state supervision. Facilities for long-term care include nursing homes, assisted living, hospitals and nursing care departments. These facilities include various wards and the designation of each resident is made according to the functional status of the residents and according to criteria intended for this purpose.

Community facilities operate much like the institutions however they are privately owned.

There are four types of wards within the various facilities:

Wards for independent residents - These wards provide care for individuals who are entirely independent in terms of daily functioning.

Wards for dependent elderly persons are dedicated to providing care for elderly individuals who have some disability and require partial assistance in their daily operations.

Full-time nursing care wards - These departments are intended for seniors with significant disabilities requiring extensive assistance on a daily basis.

Wards for elderly individuals with dementia - intended to provide care for individuals with reduced cognitive function, requiring monitoring and assistance in functioning.

Government oversight in these institutions is divided between the Ministry of Welfare and the Ministry of Health such that the wards providing care for independent and partially dependent elderly individuals are supervised by the Ministry of Welfare whereas the oversight for departments providing care to individuals requiring full-time nursing assistance and those with dementia are the responsibility of the Ministry of Health.

The Ministry of Health is responsible for the placement of elderly individuals with dementia and those requiring full-time nursing care in facilities. The funding is provided by the elderly person and his or her family however if they do not have sufficient funds to cover the costs, they are permitted to receive financial assistance from the Ministry of Health. 
This designation is limited by the budget limitations and therefore they often must wait until a bed becomes available (Koreh, 2007). Eligibility for government assistance is determined according to: the person's medical status and functional status, environmental conditions, a consultant and financial status. The Ministry of Health is in charge of 304 facilities, 11 of which are government-owned.

The Ministry of Welfare is responsible for the placement of independent elderly people and those requiring some assistance who asks to switch to assisted living or nursing homes. The Ministry of Welfare provides solutions for social issues and offers financial assistance according to an income test. The Ministry of Welfare is in charge of 167 institutions, four of which are government-owned.

The types of facilities are as follows: Assisted living is a protected living environment in the community setting that is intended for elderly individuals who are independent and interested in maintaining their own household. The main concept is the establishment of continuity from the person's previous way of life prior to entering the assisted living facility. Old age homes are appropriate for independent individuals and those with some mild physical disabilities who require partial assistance only. Every old age home provides a regular range of services to its residents, tailored to the nature of the population that lives there and their needs.

Nursing homes are intended for elderly individuals who require nursing care. Each nursing home provides uniform, basic services and they can differ based on various auxiliary services they choose to provide, as well as the level of hospitality that they offer. These types of nursing homes must be supervised continuously by the Department of Geriatrics at the Ministry of Health and operate under a license granted by the ministry.

Old Age Homes for Elderly Individuals with Dementia - for the most part these are wards within geriatric facilities, and they are intended only for individuals diagnosed with dementia who do not require nursing care.

Nursing homes on Kibbutzim (communal towns) - there are numerous Kibbutzim today that operate nursing homes on their property. These old age homes were established in the 1970s and 80s and were initially intended to serve the aging population of the kibbutzim themselves while ensuring a high quality of life in a supportive environment. Most of the nursing homes on kibbutzim are operated by private companies that are external to the kibbutz such as Amal Nursing Care, which operates a large number of these facilities (Mizrahi, 2017).

Geriatric Hospitals - Hospitals in which all of the patients hospitalized there are age 65 years and older, for example the Shmuel HaRofe Hospital (Shay, Doron, 2011, pp. 4-8).

The ownership of the nursing homes in Israel can be divided among a number of entities: First is state ownership (facilities owned by the State of Israel and that are under the supervision of the Ministries of Welfare and Health), second is public ownership (operated by a non-profit organization and other public entities under the supervision of the Ministry of Health or the Ministry of Welfare). Thirdly, there are privately owned facilities (owned by a single individual or limited company under the supervision of the Ministry of Health or the Ministry of Welfare) and finally there are foundations that own 190 institutions. The vast majority of the funding for institutional facilities is provided by the state and not private funding and includes $70 \%$ of the nursing care hospitalizations and stays at nursing homes for independent individuals and those requiring some measure of assistance (Litwin, 1996, pp. 691 -707).

Examination of the system of services for the long-term care of elderly individuals in Israel reveals that as the years go by, there is a clear trend towards a gradual transition from provision of long-term care funded by the state to care funded through mixed financing, where the state provides supervision and determines eligibility when it is the financing entity, however the provision of services is performed for the most part by private for-profit entities and volunteer non-profit organizations. Thus, the government is required by law to provide services or is interested in providing services, however they use external contractors to provide those services, meaning that the country is privatizing some of the services for the elderly - a phenomenon that is neither new nor abnormal among social services in Israel. As part of the transition towards economic liberalism in the State of Israel, the state initiated a privatization project in the 1980s, the main objective of which was to significantly reduce the direct involvement of the state in provision of services and transfer a significant portion of jobs to the private sector. Many strong believers in privatization believe that governments are generally less effective than private companies and that private companies have the benefit of a free market to implement a number of objectives:

Competition - Privatization will increase the competition between the organizations that provide welfare services and bring about an improvement in organizational efficacy (Katan, 1998, pp. 38-54). A reduction in public spending - the free market allows for the selection of a service provider based on the consumer's expectations and requirements. Quality - an increase in the quality of services, the non-government organizations are more effective and flexible and capable of providing quality service at low costs as they are not subject to the restrictions that exist in governmental organizations. They therefore have no issues with such things as new employee intake or firing ineffective 
employees, resulting in a high-quality, professional and properly trained work force (Katan, 1998, pp. 38-54). Empowerment - supporters of privatization note that having a choice and involving the consumer in the process is empowering in and of itself. Thus, is it possible that privatization is good for our elderly? Those who oppose privatization raised and emphasized their claims that private organizations are only interested in their own bottom line and not in advancing social agendas or empowerment of individualism and safety of the elderly residents. The hunger for profit, in their opinion, results in a reduction in staff working under poor conditions resulting in exhaustion. From there, the path to violence is a short one. Is this true only in Israel? It turns out that they are similar in Britain as well. According to one study (Clare, 2009), the elderly in Britain suffer from violence on the part of their caregivers at long-term care facilities where they reside as a result of improper conditions, and that is even prior to considering the fact that privatization weakens the weak. The seemingly cheaper costs eventually reached rates that many elderly people could no longer pay. Therefore they are required to wait long periods of time as the country has limited funds and the limited spaces. Thus perhaps this is the time to check the option to return to nationalization of nursing homes? Is it really true that the quality and the service are more effective when choosing private facilities? Is the title of the article published in February (Avnery, 2017) with a demand to re-nationalize the ownership of nursing homes actually what will stop the abuse of our elderly citizens?

\section{Privatization versus Nationalization of Services for the Elderly}

The number of elderly Israelis (age 75 and up) is expected to double from 610,000 in 2017 to 1.24 million by 2035, according to estimates made by the Taub Center in a review published in 2017. It is clear that the predicted demographic changes among the elderly in Israel, whose age continues to rise over the years due to a continued improvement in life expectancy, requires that a real change be made in terms of the nursing care provided to the elderly (Bitzur, 2017).

Some families are not able to contribute to the care for their elderly members and those individuals face neglect, at least to some degree, by both the state and the families. The lack of involvement by the government in the provision of care for the elderly is prominent considering the continuing rise in life expectancy. The main focus of this article deals with the dilemma between the privatization and nationalization of nursing homes in Israel. This is only one example that emphasizes the depth of the dilemma and the need to focus on solutions prior to the onslaught of the tsunami of aging.

Privatization - An attempt to transfer the responsibility for particular issues from the jurisdiction of the state to other places where they will, in theory receive better, more trustworthy, professional and dedicated management (Bitzur, 2011). As a solution to the diverse needs of the aging population and their families, we are witnesses to the rapid development of services for the elderly. The development of various services is intended to allow the elderly to continue to live safely and with the highest quality of life while maintaining independence and exercising their right to choose.

A decade ago, the nursing homes in Israel underwent privatization and the responsibility for the fate of thousands of elderly citizens was transferred to private hands (privatization) instead of the government taking responsibility for its elderly citizens (nationalization). Private entities began to operate for their own profit and took over one of the areas of welfare. Privatization is not a new or abnormal phenomenon in the field of provision of social services in Israel, and signs of privatization had been seen before among provision of social services, including those provided to the elderly.

In recent years, privatization has grown and the belief of various economic and political perspectives maintain that privatization is the recipe for the repair of all failings of the social services in which the government plays a central role (Katan, 2011, pp. 39-58). Privatization has taken over 21 thousand elderly people requiring nursing care in Israel distributed throughout 340 institutions. The Ministry of Health admits that during 2016, they made just 11 nighttime visits. The result is that $98 \%$ of the nursing homes were never once evaluated by the Ministry of Health. The lives of the elderly people are in peril. On the one hand, their lives are under the control of the institutions, whose management has profit-oriented motivations. On the other hand, there is a reality of a lack of oversight. If it exists, it is miniscule and lacking (Kalinsky, 2018). The number of staff positions has been reduced and subject to no state regulation. When the number of positions is downsized, the private companies save money, and with no regulation, they forget that the welfare of the elderly under their care should be their guiding principle and that the neglect, inadequate environment and violence are all a part of the sad and terrifying results of privatization. In addition, research shows that private institutions frequently cut funding in the crucial areas for the quality of care for the elderly, such as cuts in staffing or medical equipment, resulting in overworked staff caring for the residents and a risk for harm and neglect to the elderly under their care. There are those that consider privatization to be the "original sin", not only because it is wrong but also because it is a lifeline, high quality fuel for growth and development. It promotes competition and without it, the economy would be poorer, slower with a higher rate of unemployment and a lower quality of life. It is fair to say that we are lucky that in the mid-1980s, our leadership was brave enough, not populist and did the right things without asking the people what they wanted. They made decisions, performed privatization and promoted reforms thereby 
increasing the growth and development that we enjoy today. As a result, today we have a more evenly distributed, stronger and more resilient economy (Shtresler, 2009).

Some claim that the healthcare system in Israel is undergoing a process of privatization that is resulting in negative outcomes, especially due to the inequality that exists within the system. However, when examining the main parameters and their position on the spectrum between the free market and government control, a more complex picture is revealed. While some measures indicate growth in private funding, other measures point to certain growth in public funding. The privatization process requires consideration within a comprehensive policy framework that might clarify again the responsibility of the state within the field of health care that has become somewhat unclear. Eckstein and others agree, "Privatization, in the most specific manner, refers to the reduction of the involvement of the government in the production process." This involvement is can be seen on two levels: through the rules, ordinances, and regulations and the direct manufacturing of products and services for use by the general public. On the second level, it deals with the transfer of government manufacturing to private hands. In this regard, we can distinguish between three groups: First public services (i.e. security, education, welfare) which are provided for free, second, services on a local or municipal level (water, waste removal) provided for a fee (whether general or specific) and third, products that create business units that are owned by the government but are sold on the free market to private consumers in exchange for money such as electricity, water, postal and communication services as well as entirely private services such as: transportation, fertilizers, coal, oil, and iron. Privatization in its more limited definition relates to a group of government companies, and its significance is the transfer of control over these companies to private ownership through the sale of shares in the state to private investors (Peleg, 2005, pp. 19-20).

The privatization process is performed by Government Companies Authority, which was established by virtue of the Government Companies Law. Privatization processes include: promoting and implementing privatization processes, preparation of the companies for these sorts of moves, consulting to the Ministerial Committee for the Privatization regarding the ways and privatization processes, coordination between various entities and management of the execution of the privatization process both in terms of private sales as well as through public offerings (Hasson, 2006, pp. 9-22).

The legacy of privatization is based among other things on the early thoughts of Adam Smith who believed that the country is not the most effective process for the management of economic businesses. "Today as well, this is the main reason for privatization." In this regard, regarding the privatization of government companies, it was also written that, "the accepted claim is that the government (any government) is not good at managing business and therefore government businesses are less effective than private companies and their sale to private individuals will increase their effectiveness, thereby improving the effectiveness of the entire economic system. This is a concept that sits at the foundation of the entire issue of privatization."

The effectiveness that these claims describe is effectiveness for the manufacturer, the private entity. This is not necessarily for the individual receiving the actual service. The cost savings also relates to a reduction in expenses for the authorities in charge of maintaining specific procedures to ensure that fair decisions are made for the citizens.

Ruth Ben Israel notes that the efficiency approach views the public sector as ineffective since it operates not only from a place of economic considerations but also considers social, political and other elements. The consideration of these elements deviates from the rules of the market of supply and demand, meaning that the integration of a non-economic considerations results in distortion of the effective allocation of resources on the market. Another approach to the element of efficiency considers the private driving forces (motivation) - the compensation method in the public sector does not correlate the employees' income with the extent of his or her success in the workplace. This method is contrary to human nature, which tends to increase efficiency in production when offered direct financial gain. According to this approach, privatization that transforms a privately owned public organization will achieve this missed efficiency in the workplace thanks to the private-sector compensation system, which focuses on initiative, creativity and efficiency. This argument seems to be the strongest, however it focuses on the efficiency of the employee and thereby directly connects it once again to efficiency from the perspective of the manufacturer.

The third aspect of efficiency lies in the argument that administrative bureaucracy is corrupt. The public administrative bureaucracy has basic motivation to perpetuate the organization and increase its power. The public workers have no incentive to increase efficiency within the system, as increased efficiency in operations will exhaust them and even cost them their jobs. The privatization thereby improves efficiency and reduces these bureaucratic anti-efficiency mechanisms. In any event, it is clear that the senior citizens in Israel are harmed by the problematic approach to efficiency and thus privatization is preferable.

In addition to this, scholars note that there are a number of fiscal tasks related to privatization: First is the release of the country from the burden of failing government companies (resulting in regular budget savings), secondly is the release from the burden of investments in development of government companies (savings on the development budget) and 
thirdly, the sale of government companies as a source of income for the Ministry of Finance, which in Israel was the main objective of the privatization plan. Does this help our elderly access the residential arrangements they want? It is quite unlikely.

The temptation to solve fiscal problems and finance a budget deficit easily is prominent, although the economic cost involved is not always as clearly defined. The privatization, according to those who advocate for it, will express the freedom of will, bring about efficiency and stop waste, reduce requests for loans from the public sector, bring about control over wages in the public sector, weaken the power of trade unions, transfer business decisions from politicians to businessmen, expand the number of shareholders among the public in general and among the workers in particular, and mostly, increase efficiency in the economy by promoting liberalization and competition. The efficiency argument however largely ignores the question: Are we promised efficiency from the perspective of the citizen receiving care following privatization? (Peleg, 2005, pp. 19-20). It is surprising that up until 1977 in Israel there were no clearly defined goals as a stated political objective. It was only the political upheaval the same year that brought about an official statement by the government that they would reduce their involvement in the national economy and their exposure to the market forces. However it was only in 1985, with the establishment of the economic plan for economic stabilization that a series of detailed objectives was announced as an explicitly political decision. In a hearing on the subject held in 1987, all of the speakers reached the conclusion that "there is no agreement in Israel with regards to the significance of privatization in Israel". At the same time, Zeev Refua, the Director General of the Government Companies Authority at the time said, "the objectives of the privatization were first and foremost a reduction in the state's involvement, second, raising of capital, and third, an increase in the free market competition." Only in 1993 did the Israeli government adopt a list of objectives submitted by the director of the Government Companies Authority at the time, Yosef Nitzani. Emphasizing an expanded range of objectives as well as adoption of an amendment to the Government Companies Law to include the following privatization objectives as well:

1. Increase in economic efficacy for the improvement of the competition in the economy.

2. Raising of capital from the local market by the government.

3. Creation of employment sources by strengthening the private sector

4. Expansion of the foundation of the stock market

5. Raising foreign capital and development of new markets.

There is a notable absence of a specific objective that is mentioned in most countries, which is an improvement in the distribution of "national assets" and the income that results from them (Eckstein, et al, 1998, pp. 59-86).

\subsection{Types of Privatization Methods}

Method 1: Sale of most or all of a company through the issuance of shares to the public via the stock market. The government transfers the control of the company to private hands. Method 2: Sale of part of the company by issuing shares to the public through the stock market. The main principle in this method is that the government sells less than 50\% of the company, leaving the control in the state's hands. Method 3: Private sale of shares. In this method the government sells their part in the company (either partially or entirely) to a single buyer or a buyers group. Method 4: Selling parts of the government company. Sometimes this method is utilized in order to dispose of specific activities by the company and sometimes it is used as a method for selling the entire company. Method 5: Restructuring (or division of the company) - selling the entire company. For this purpose the company is divided or restructured into separate sub-companies or holding companies with sub-units. Method 6: New private investment for government companies. The government does not sell their portion but rather increases the capital of the company by adding investors from the outside resulting in dilution of their portion. Method 7: Sale to management and employees - using this method, a limited number of managers or partnerships between the directors and the employees purchase control of the company. Method 8: A lease and management contract - in this method, the government company is granted management or private technology in exchange for assets and payments. This method provides the private entity with an incentive to improve the company's situation as well as the option to become intimately familiar with the company's potential, its activities, and its employees without the risk involved in its acquisition.

There are three main types when it comes to the concept of privatization: first, there is market privatization. Supporters of this type emphasize the transfer of activity in the field of welfare services to the economic market. This type, for the most part, represents economists from more conservative schools of thought who see the economic market as a tool capable of providing the best solution to all problems related to supply of services. According to their opinion, market factors such as competition, profit motives and free choice that the market can provide are preferable to collective supply. Correction of market failures is, in their opinion, just as bad as the disease itself (Wolf, 1997) and therefore they are opposed to correcting market failures through collective supply because of their unequivocal belief in market 
superiority. They are firm in their belief that the state's supply is worse than the market supply because of the structural pathology of public institutions of a bureaucratic nature. It is this pathology, which results from an absence of competition, uncontrolled growth, a lack of regulation and control over the output, the failure to provide consumers with options, etc. that requires the transition to privatization.

Secondly, in conservative privatization the focus on this type is not a return to an economic market and the fundamentals of its competition but rather, according to the conservatives, an effort re-strengthens the natural foundations of the company. Supporters of this type do not accept the assumption of market superiority in advance but rather prefer an alternative to the state's operations in the field of welfare, the operation of the small and informal entities such as volunteer organizations, local community organizations, and associations for providing self-assistance, etc. Their preference regarding everything related to welfare institutions, in sociological terms, is that of "intermediary structures", which in are structures that have solutions that are inherently less bureaucratic, more direct and smaller in size for solving human problems. Although this approach to privatization might be considered more moderate, it also includes the basic denial of welfare services being provided by the state, as Yatziv found in his research.

Third is radical privatization which offers extreme, conservative romanticism calling for the abolition of any state intervention in the field of welfare and other operations. In the eyes of supporters of this approach, intervention by the state is the root of all evil in contemporary society. Most supporters of this approach come from the margins of the extreme right and demand a drastic reduction in the state's role as well as limitation to the activity for preservation of private property only. Only total protection of private ownership and private supply with total privatization of all public ownership and all public operations is an acceptable solution in the eyes of those who support this approach and they are willing to act to ensure that their views are realized (Doron, 1989, p. 23).

The numerous advertisements in daily newspapers and on the radio from various organizations offering the aging population residential facilities and old age homes with attractive names, which compete with one another to offer attractive payment options and assure the highest quality of life might make the impression that the market economy has deepened its reach into the field of institutional services for the elderly and marginalized the government entities. Examination of the concrete information available that deals with the involvement of the government and non-government organizations in the field indicates that this impression is only partially justified. The government has reduced its role as the supplier of institutional services, however continues to fulfill a central role in the financing and purchasing of said services and the oversight over their operations. The roles of the government and the non-governmental organizations in the funding, supply, regulation and establishment of conditions for receiving institutional services will be described below. There is no doubt that these roles delay the privatization of the services for the aging with their nationalization and that is likely the ideal model for caring for our elderly. First of all, in funding of the institutional services, the government fulfills a central role in the funding of institutional services for the elderly. Government assistance can be expressed in two main forms: funding for the care for elderly in various institutional settings and assistance in development of institutions and improvement of their physical infrastructures. The data teach us that the main role fulfilled by the government in the financing of the residents' stays in the institutions, especially those requiring constant nursing care, partial nursing care and those with dementia. Second, the provision of institutional services - Is the main role fulfilled by the government in their funding of institutional services reflected in their involvement in the provision of those services? What is the role of the government and additional public entities that own facilities for the elderly? Not only does the government subsidize them, they are also subsidized by non-government organizations (NGOs) in Israel.

NGOs play a crucial role in providing services to the elderly. The privately owned organizations account for more than $60 \%$ of the total growth that has occurred in the number of residents at facilities for the elderly. The privately owned institutions continue to embolden their status in this arena. Third, the regulation and oversight over the services: The government continues to fulfill a central role in the regulation and oversight over the institutional services provided to the elderly. The government regulation applies both to organizations receiving government assistance and those who receive no financial assistance whatsoever. The Ministry of Labor and Welfare handles the oversight of facilities for independent elderly residents and those requiring partial care while the Ministry of Health is in charge of the oversight for facilities that provide care to those requiring full-time care and those with dementia. These ministries provide the institutions with licenses that allow them to operate and in the same regard, they are even permitted to withdraw these licenses when they do not meet the regulatory requirements. In fact, in keeping with their supervision requirements over the years, the government ministries have imposed closure orders on institutions that failed to provide their residents with an adequate standard of living (Fleishman, et al, 1994-5, pp. 11-25).

The government ministries therefore play a central role in the supervision and oversight of the institution's activities. It should also be noted that as organizations receiving government funding, many of the facilities for the elderly are subject to review by the State Comptroller, as well. 
The following table summarizes the roles fulfilled by the government and other entities in the field of provision of institutional services to the elderly:

\begin{tabular}{llll}
\hline & Government & Other Organizations & Residents and their Families \\
\hline Financing & Central & Partial & Central \\
Supply & Limited & Central & Partial \\
Oversight & Central & Partial & \\
\hline
\end{tabular}

The realm of institutional services for the elderly in which the government ministries, volunteer organizations, private organizations - businesses and consumers - play an active role, serve as a clear example of the "combined economy" in which we see two main types of division of labor between the various entities. One type is characterized by a high level of involvement by the state in the funding and purchasing of services that are supplied by other organizations. The state even refers residents to institutions based on criteria that they themselves established and determines the payment for their stays there. This type is characterized by a tendency towards nationalization however there are also components characteristic of principles of privatization - the supply of services is executed for the most part by non-government organizations and the employees responsible for referring residents can choose among a number of institutions and prefer those that offer higher quality services. In many cases, the right to choose an institution is in the hands of the residents themselves and their family members, who choose an institution from a list provided by the employees who handle these matters. The existence of an element of choice may encourage inter-institutional competition. The second type is characterized by the tendency towards privatization and market economics. There are institutions that offer institutional services. These institutions compete with one another over potential residents. Within this competition and the marketing efforts, the institutions provide information regarding the cost of stays and the range and quality of services they will receive. The institutional services for the elderly in Israel are therefore a model of partial privatization and a mixed economy in which there are different levels of involvement and power in the different sectors. In the face of partial privatization, nationalization is a prominent factor upon which we will focus in the next sections.

Nationalization - The antonym of privatization is nationalization. Nationalization is a term that describes the act of taking property from its owner by the state and conversion of said property to national property. While the term is typically used to describe the repossession of private property, it is sometimes used to refer to the seizing of property belonging to the local authorities. There is a position that supports the return of ownership and oversight over long-term care facilities to the state, meaning nationalization of these facilities. The state currently owns $4 \%$ of long-term care facilities and the rest are owned by various other entities. This position supports the abolition of privatization due to the difficulties that exist in regulation of long-term care facilities and in light of the state of some of these facilities in Israel.

Nationalization exists when the state is responsible for all four dimensions of the social services, i.e. the funding, supply, establishment of rules of entitlement, and supervision and control. In Israel, as the years go by, there is a clear trend of gradual transition in most of the services for long-term care (old age homes) from a model of nationalization to a pattern of a mixed economy, including privatization. The concept of nationalization is familiar and well known in the world. One example of nationalization is how the United States nationalized Amtrak and mortgage companies.

In Israel, with the establishment of the state, the tendency was towards nationalization. The first Prime Minister, David Ben Gurion, nationalized the electricity company, which was founded 30 years prior to the establishment of the State of Israel as a private company. Over the years, the great advantages of privatization, a process by which the State transfers the service or product to private ownership, became clear. Now, after 70 years, the state is holding negotiations regarding the privatization of electricity from the hands of the monopoly that is the electric company. Even in democratic countries like Israel, the state is always involved in business, however its involvement is a golden partnership - the state does not participate in investments and is not party to losses, but receives it share of the profits. When the state has ownership of a company, it is committed to the investments in that company, financial losses and almost never enjoys the profits as the state is not a for-profit organization (Topaz, 2017). In contrast to the principle of nationalization, which holds that the state must fully direct social services through total control over their funding, supply, determination of entitlement to said services and regulation over their operations, the idea of privatization favors the complete departure of the state from the arena of social services and submits the total responsibility for the field into the hands of NGOs.

One of the main issues where these opposing views have been expressed is in the dispute between those who support the state and recognize the importance of its influence over society, and the advocates of a civil society who emphasize the importance of civil organizations that grow freely from within society and represent the different and diverse interests of the civilians. The idea of privatization strives to reduce the influence of the state to a minimum and provide a channel for entrepreneurship and the inherent capabilities of the individuals and various organizations that make up the civil society. Advocates of nationalization note that the state was established to serve its citizens. A welfare state will promote social agendas while private organizations fail to promote social issues, and the continued involvement of the state is crucial in order to ensure the social solidarity and prevent harm to the weaker layers of society that are economical disadvantaged. 
In addition, the break down of the welfare state and the privatization of the social services are the main factors contributing to the growth of inequality in Israel and the degeneration of crucial systems not only for the welfare of the individual but also for the strength of the economy as a whole (Gutwin, 2012, pp. 12-48). Currently, we are bearing witness to an effort to nationalize the funding for long-term care insurance; the Ministry of Health has asked to fund the reform by raising the health care tax by $0.5 \%$. According to the plan by the Ministry of Health, the reform will increase the number of weekly hours of nursing care providing to individuals requiring nursing assistance who live at home by $50 \%$ (from 22 to 33 weekly hours). In addition, a budget will be allocated to support family members who care for their elderly relatives and there will be a reduction in earning tests used to determine if a family is eligible for government assistance for determining the extent of the public funding that will be granted to the elderly requiring nursing care, including elimination of earning tests for the families. The Ministry of Finance opposes the reform and the proposed funding plan (Nationalization of Nursing Care, 2017). Of course, the question is whether this trend will stop here or if, because of the attempt at nationalization, it indicates that it is still possible to find remnants of welfare and consideration of the weaker population and that it will return to its previous state and the long-term care facilities will once again be nationalized in light of the numerous cases of violence and neglect of the elderly in these facilities now.

\section{Conclusion}

Our aging population, the increase in life expectancy, the progress and the technology have created a situation in which systems everywhere, especially in Israel, must prepare in advance to provide health care, food, culture, employment, funding and housing for our elders. The many dilemmas our decision-makers face regarding the elderly must be handled from the foundations, comprehensively on the one had but on the other, we must also focus on acute issues such as housing. Housing is at the core of the various challenges of an aging population. The questions of whether an elderly person will live in assisted living, a nursing home or a community setting is a key question that must be answered to ensure proper care for our families, parents and the people who are our parents and the founders of the nation that we call home. The second question in the world is whether the state should take full responsibility for the elderly (the Scandinavian model) or allow the private market to do what they do regarding provision of services for elderly people, particularly on the matter of housing. Are we responsible for funding, maintaining, caring for and protecting our elderly with the type of housing that we choose for them or should we allow the market forces to do what they do best in order to perhaps achieve better and higher quality results and for these individuals, whose ages we rapidly approach ourselves?

A model that integrates privatization with national oversight and regulation provides a better solution than others, however it is also not perfect and as we already mentioned at the beginning of this article, we do not pretend to solve the problem, but it is our duty to inform the public.

\section{Notes:}

1. Avi Bitzur, Ph.D. Head of the Department of Gerontology, Faculty of Education, Beit Berl Academic College. Former Director of the Ministry of Senior Services, Government of the State of Israel.

2. Mali Shaked, Chief of Staff of the Friends of Meir Medical Center Foundation, Kfar Sava, holds a Bachelor's degree in Health Systems Management with a major in Applied Gerontology and currently completing a Masters degree in Business Administration specializing in Human Resources.

3. WHO - The World Health Organization established by the United Nations in April of 1948 to handle the issue of health care around the world.

\section{References}

"From Nationalization of Funding for Long Term Care Insurance" (2017). Privatization and Nationalization in Israel. Van Leer Institute in Jerusalem. Accessed at http://hafrata.vanleer.org.il

"The phenomenon of abuse in the institutional system in nursing homes," Or Information Center. Accessed 1 May 2018 at http://www.orcare.co.il/gilhazahav/hitaliloot-bkshishim/tofaa-hetaliloot

Avneri, A. (2017). In order to Protect Our Elderly, we Must Nationalize Old Age Homes. Sicha Mekomit. Accessed at: www.mekomit.co.il/steream

Be'er S. (2004). "Research Report: A Survey of Long-Term Care Facility Residents" Accessed at: http://brookdale.jdc.org.il/wp-content/uploads/2018/01/429-ltc-heb.pdf

Be'er S., \& Factor, H. (2010). Facilities for Long Term Care and Assisted Living Programs: The Status in 1989 and Developments Over Time. The Brookdale Institute, Jerusalem, pp. 1-51.

Be'er, S., \& Factor, H. (1993). "A National Census Over Residents of Long Term Care Facilities and Assisted Living Plans". Gerontology, 62, 16-38. 
Berman, A. (1988). "The Biology of Aging”, from Jewish Law and Medicine, part 6. Jerusalem: The Schlezinger Institute, pp. 40-56.

Bitzur, A. (2001). "Privatizing the Seniors" The Pulse, accessed at: https://thepulse.co.il/index.php/מפריטים-את-הגמלאים-/ד-ר-אבי-ביצור/

Bitzur, A. (2017). "Healthcare and Treatment of the Elderly is at a Moral Low" YNET Accessed at: https://www.ynet.co.il/articles/0,7340,L-5012289,00.html

Bitzur, A. (2018). "Five Moves For Preventing Elder Neglect" Davar Rishon. Accessed at: https://www.davar1.co.il/1741112

Bitzur, A. (2018, April 4). "The Age Pyramid Has Flipped Upside Down” JOKOPOST.COM . Accessed at: https://www.jokopost.com/society/17199

Brenner, Y. (2001). “A Long Life - Changes Throughout Human History”, The Tnuva Research Institute, 52. pp. 5-12.

Brodsky, J., \& Davis, M. (2003). "Demographics and Epidemiology, Aging and the Elderly Population”, from Aging and Old Age in Israel, Arnold Rosen, Eshel - The Foundation for Planning and Development of Services for the Aging, pp. 289-313.

Clare, 1. (2009). "Is nursing's great challenge care of the elderly?", Nursing Time, Accessed at: https://www.nursingtimes.net/is-nursings-great-challenge-care-of-the-elderly.

Doron, A. (1989). "Privatization of Welfare Services: The Site of a New Battle Over the Image of Israeli Society". Social Security, 34, 18-23.

Dror, R. (2014). "Examination of Methods for Handling Loneliness Among the Elderly." Accessed at: https://www.btl.gov.il/Funds/Special\%20Activities/Documents/DochVaadatBdidut.pdf

Eckstein, S., Zilberfarb, B., \& Rozavitch, S. (1998). Privatization of Companies in Israel and Abroad. Ramat Gan. Published by Bar Ilan University, pp. 59-86.

Fleishman, R., Mizrahi, G., Dinia, A., Shirazi, H, \& Shapira A. (1994/5), "Improvement of the regulation over treatment quality." Gerontology, 67, 11-25.

Gutwin, D. (2012). "Nationalization, Let's Talk About It". Hevra, 53, 12-48.

Hasson, Y. (2006). "Three Decades of Privatization”, The Adva Center, pp. 9-22.

Haviv, J., \& Shneor, Y. (2003). "Economic Implications of Aging on Society", Aging and Old Age in Israel, Arnold Rosin, Eshel - The Foundation for Planning and Development of Services for the Aging, pp. 715-732.

Inbar, N. (2014). "In 2035, the senior citizens in Israel will number 1.6 million", Emago. Accessed at www.e-mago.co.il

Kalinsky, A. (2018). "The Dependency Test" Joint Israel, Ruth Information Center. Accessed at: https://www.reutheshel.org.il/\%D7\%9E\%D7\%91\%D7\%97\%D7\%9F-\%D7\%94\%D7\%AA\%D7\%9C\%D7\%95\%D7 \%AA-\%D7\%9C\%D7\%A9\%D7\%9D-\%D7\%A7\%D7\%91\%D7\%9C\%D7\%AA-\%D7\%97\%D7\%95\%D7\%A7-\%D 7\%A1\%D7\%99\%D7\%A2\%D7\%95\%D7\%93-3/

Katan, Y. (1998). "Institutional Services for the Elderly: A Sample of Partial Privatization". Gerontology, 77, 38-54.

Katan, Y. (1998). "Personal Welfare Services in Israel: Central Issues and Dilemmas” from Social Security 53, pp. 39-58.

Katan, Y. (2001). "Implementation of Privatization Policy in Long Term Care Insurance, Primary Lessons". Social Security, 60, 129.

Kitchener, M., Miller, M., \& Harrington, C. (2006). " Institutional and community-based long-term care a comparative estimate of public costs", From: www.ncbi.nlm.nih.gov/pubmed/17255071

Kofi, Y. (1996). Designation of Resources for Social Services 1996, The Center for Social Policy Research in Israel, Ramot, pp. 1-19.

Koreh, M., \& Chernikovsky, D. (2007). Reforms in the Management and Funding of Long-Term Care in Israel: A Research Report. Accessed at: https://www.aisrael.org/_Uploads/dbsAttachedFiles/13878m02010.pdf

Koretz, M. (2003). “Aging in Jewish Tradition” from Aging and Old Age in Israel, Arnold Rosin, Eshel - The Foundation for Planning and Development of Services for the Aging, pp. 5-7.

Levenstein, A. (2003). "Intergenerational Interactions in the Aging Family", Aging and Old Age in Israel, Arnold Rosin, Eshel - The Foundation for Planning and Development of Services for the Aging, pp. 629-631.

Litwak, K. (1985), Helping elderly, New York: Guilford, pp.18-60. 
Litwin, H., \& Lightman, W. (1996). "The development of community care policy for the elderly: A comparative perspective". International Journal of Health Services, 26, 691-707. https://doi.org/10.2190/387A-F71L-QADX-9BP7

Machtinger, R. (2010). "The Elderly Population in Israel”: A Research Report from the Interdisciplinary Center, Herzliya. Accessed at http://www.herzliyaconference.org

Mizrahi, A. (2017). "Geriatric Hospital”. Accessed at: http://www.geriater.co.il

Mizrahi, Y. (12 Feb 2017). "Documented: Elder Abuse at Nursing Homes". Mako. Accessed at: https://www.mako.co.il/news-israel/local-q1_2017/Article-adab832d0925a51004.htm?Partner=searchResults

Peleg, A. (2005). Privatization as an Accumulation of Privatized Entities in Public Law. Tel Aviv, Ramot 19-20.

Rosen, A., Eshel - The Foundation for Planning and Development of Services for the Aging, pp. 289-336.

Shai, K., \& Doron, Y. (2011). “The rights of residents in nursing homes and other institutions," The Legal Foundation for the Rights of the Elderly. 4, pp. 4-8.

Shtresler, N. (11 August, 2009). "Privatization is Good". Haaretz. Accessed at https://www.haaretz.co.il/opinions

Topaz, R. (2017). "Once Nationalized, Now Privatized" Israel Today. Accessed at: http://www.israelhayom.co.il/article/514859

Yakobovitch A. (2011). Innovative Plans For the Handling of Disabled Elderly: Research Report. Accessed at: https://www.btl.gov.il/Publications/research/Documents/mechkar_105.pdf

Yakobovitch, A. (2014). “Aging In Place: From Theory to Policy and Practice”. Gerontology and Geriatrics, MA, 2. pp. $15-35$.

Zaira, J. (2017). "Data Regarding Senior Citizens, Aging and Old Age in Israel", Report HLMS. Accessed at: https://www.knesset.gov.il/mmm/data/pdf/m04093.pdf

\section{Copyrights}

Copyright for this article is retained by the author(s), with first publication rights granted to the journal.

This is an open-access article distributed under the terms and conditions of the Creative Commons Attribution license which permits unrestricted use, distribution, and reproduction in any medium, provided the original work is properly cited. 